\title{
Capacity, Control, or Both - Which Aspects of Working Memory Contribute to Children's General Fluid Intelligence?
}

\begin{abstract}
Starting from the assumption that working memory capacity is an important predictor of general fluid intelligence, we asked which aspects of working memory account for this relationship. Two theoretical stances are discussed. The first one posits that the important explanatory factor is storage capacity, roughly defined as the number of chunks possible to hold in the focus of attention. The second one claims that intelligence is explained by the efficiency of executive control, for instance, by prepotent response inhibition. We investigated 96 children at the age between 10 and 13 . They completed a version of the n-back task that allows assessment of both storage capacity and inhibitory control. They also completed Raven's Progressive Matrices as the fluid intelligence test and the Test for Creative Thinking - Drawing Production, for control purposes. We found that Raven's scores correlated negatively with the number of unnecessary responses to irrelevant stimuli but they did not correlate with the number of signal detections. We conclude that children's fluid intelligence depends on inhibitory control, with no relationship with storage capacity.
\end{abstract}

Key words: working memory, intelligence, $n$-back, schoolchildren

Working memory is believed to be not only "a memory", that is to say, one of several modules involved in information storage and retrieval, but also the central "engine" for human higher-order cognition (Hambrick, Kane, \& Engle, 2005; Nęcka \& Orzechowski, 2005). Numerous studies demonstrated that efficiency of this "engine" accounts for individual differences in reading skills (Daneman \& Carpenter, 1880; Henry, Messer, \& Nash, 2013), verbal comprehension (Daneman \& Green, 1986; Daneman \& Merikle, 1996), mathematical skills (De Smedt, Janssen, Bouwens, Verschaffel, Boets, \& Ghesquière, 2009), problem solving (Nęcka \& Orzechowski, 2005; Oberauer, Süß, Wilhelm, \& Sander, 2007), and - last but not least - general fluid intelligence, Gf (Chuderski \& Nęcka, 2012; Kyllonen \& Christal, 1990; Nęcka, 1992). Some authors went as far as claiming that working memory capacity (WMC) is almost synonymous with Gf (Colom, Rebollo, Palacios, Juan-Espinosa, \& Kyllonen, 2004; Kyllonen \& Christal, 1990), although available empirical evidence is not that convincing (Ackerman, Beier, \& Boyle, 2005). Nevertheless, there are no doubts that general fluid intelligence, understood as the domain-general ability "to reason, plan, solve problems, think abstractly, comprehend complex ideas, learn quickly and learn from experience" (Gottfredson, 1997, p. 13), is at least moderately, and sometimes strongly, correlated with various measures of WMC. It is estimated that WMC and Gf share from at least $50 \%$ (Kane, Hambrick, \& Conway, 2005 ) up to $70 \%$ (Oberaurer, Schultze, Wilhelm, \& Süß, 2005 ) or even $90 \%$ (Colom et al., 2004) of variance. The relevant studies are mostly correlational so it is hard to decide about the direction of causation, although cognitive psychologists usually believe that processes involved in working memory functioning constitute the substrate of Gf (see: Oberauer et al., 2007).

Having established that WMC is one of the strongest predictors of Gf, researchers focused on the more detailed issue, namely, which aspects of working memory contribute

\footnotetext{
* Jagiellonian University in Kraków

** The University of Social Sciences and Humanities, Warsaw

Correspondence concerning this paper should be addressed to Edward Nęcka, Jagiellonian University, Department of Psychology, ul. Ingardena 6, 30-060 Kraków, Poland. Contact: edward.necka@uj.edu.pl
} 
to intelligence. Working memory is a construct referring to complex cognitive machinery, consisting of the central executive, active and passive storage modules for verbal material, as well as active and passive storage modules for nonverbal content (Baddeley, 1986; 2002; Baddeley \& Hitch, 1974; Miyake \& Shah, 1999). It is therefore necessary to understand which of its components are important for intelligence, and why. From the perspective of the psychology of individual differences, two explanations of the WMC and Gf relationship have been proposed. Proponents of the first account (e.g., Cowan et al., 2005; Cowan, Morey, Chen, \& Bunting, 2007) emphasize the role of storage capacity, understood as the number of items possible to be maintained and processed within the focus of attention. It is well established that human short-term storage capacity is severely limited, since we are able to keep in the primary memory, also called the focus of attention, between two and six chunks of information, the average capacity being about four (Cowan, 2001). It is claimed that the more capacious focus of attention the higher the cognitive abilities of a person, because thinking and problem solving presumably need permutation of objects held in the active memory. A variation of the "capacity approach" amounts to the thesis that objects held in the primary memory must be bound temporarily to task-relevant structures, such as the words a phrase consists of (Oberauer et al., 2007; Oberauer, Sü $\beta$, Wilhelm, \& Wittmann, 2008). Such temporary bindings must be quickly substituted by the new ones in order to allow further cognitive processing. For instance, verbal comprehension needs quick formation and replacement of temporary bindings referring to the syntactic and semantic characteristics of the successively incoming messages. It is claimed that individual cognitive ability of a person depends on the number of elements that can be bound temporarily in the primary memory according to the requirements of the task at hand. Proponents of the second account (e.g., Engle \& Kane, 2004; Engle, Tuholski, Laughlin, \& Conway, 1999; Kane \& Engle, 2002; Kane, Conway, Hambrick, \& Engle, 2007) underscore the role of attentional control, roughly reminding Baddeley's (1986) idea of the central executive. It is claimed that storage capacity does not suffice for effective intellectual functioning if attention is not focused on the relevant chunks of information. This line of reasoning is closely related to the theoretical accounts of Gf in terms of the efficiency of executive control (e.g., Friedman, Miyake, Corley, Young, DeFries, \& Hewitt, 2006; Gray, Chabris, \& Braver, 2003).

The "capacity approach" and the "control approach" (Chuderski \& Nęcka, 2012) are not only two competing accounts of the WMC-Gf relationship but also two strands of theorizing on the nature of WMC itself. It is important to realize that the term "capacity" is usually used in the literature in its broad sense, meaning the general efficiency, or efficacy, of the mental machinery of working memory. This general efficiency probably depends on both the size of the focus of attention and the effectiveness of attentional control. Joint contribution of these two factors defines individual level of the compound cognitive skill called "working memory capacity", or WMC. In its narrow sense, the word "capacity" refers only to the storage aspect of working memory. Within the original framework outlined by Alan Baddeley (1986; Baddeley \& Hitch, 1974), capacity in the narrow sense may be defined as the number of elements possible to be held and maintained by the articulatory loop or by other modules responsible for shortterm storage. Analogically, within the model suggested by Nelson Cowan (2001), capacity understood in the narrow sense may be defined as the size of the focus of attention. In this paper we use both meanings, depending on the context. If we refer to the WMC-Gf relation, we use the broader meaning, but if we refer to particular theoretical accounts of the WMC-Gf link, we use the word "capacity" in the narrow sense.

Going back to the nature of the WMC-Gf link, it is difficult to judge which of the two competing accounts is more compatible with empirical results. Majority of relevant studies used complex span tasks as measures of working memory capacity, such as the OSPAN task (e.g., Kane \& Engle, 2003; Turner \& Engle, 1989). These tasks need both capacity and control, and researchers have limited opportunities to split those two aspects of working memory in order to decide which of them contributes to particular cognitive skills. Additionally, the mere complexity of span tasks make them likely to correlate with scores obtained with intelligence tests, which are also rather complex cognitive tasks.

In a series of six experiments with normally functioning adult participants, we (Chuderski \& Nęcka, 2012) tried to confront these two lines of theorizing. Instead of relying on complex span tasks, we used several versions of a relatively simple task called $n$-back (Kirchner, 1958; McErlee, 2001). This task requires constant updating of the contents of working memory, being a good estimate of the capacity aspect of WM. The logic of n-back consists in continuous presentation of items (e.g., numbers, figures) that appear and disappear one by one. The task is to decide if the currently presented item has already appeared $n$ items back. In the following hypothetical stream of stimuli: $46, \underline{58}, 32, \underline{58}$, and so forth, the last item 58 has already appeared two items back. The $n$ number is usually manipulated from one to four, thus allowing estimation of accuracy of participants' decisions in relation to the level of difficulty of the task's conditions. In some versions, the n-back task also needs efficient executive control, since certain items may reappear at wrong positions. For instance, if the $n$ number is defined as 2 , the following stream: $46, \underline{58}, \underline{58}, 32$, and so forth, includes a lure, which is the item 58 reappearing too early. Sometimes lures appear too late, i.e., after the predefined $n$ number. Participants must abstain from responding to lures in order to avoid errors, although they are "tempted" to press a button in response to an ostensibly valid signal. Abstaining from lures needs efficient executive control, particularly the function of prepotent response inhibition (Miyake et al., 2000). Thus, the n-back task allows assessment of both capacity and control aspects of working 
memory. The former is assessed on the basis of accuracy of target detection, whereas the latter is estimated on the basis of lure neglect. We found that storage capacity explained as much as $62 \%$ of variance of Gf, whereas executive control explained only 13\% (Chuderski \& Nęcka, 2012). Thus, both aspects of working memory, storage and control, appeared important but the former outstandingly surpassed the latter. Another study (Chuderski, Tarady, Nęcka, \& Smolen, 2012), carried out with the structural modeling approach, revealed that storage capacity explained as much as $70 \%$ of Gf variance. Attention control explained about $25 \%$ of Gf variance but its significance disappeared when storage capacity was statistically controlled for.

In this paper, we address the same question pertaining to children aged 10-13. A rationale for this study originates from the assumption that the proportion of Gf variance explained by two competing factors - storage capacity and executive control - might depend on the dynamics of cognitive development. It has been demonstrated that executive control develops very quickly between three and seven years of age (Białecka-Pikul, 2012; Eisenberg, Duckworth, Spinard, \& Valiente, 2012; Rothbart \& Rueda, 2005; Rueda, Posner, \& Rothbart, 2005) but it is far from stabilization at the pre-adolescent period (Casey, Getz, \& Galvan, 2008). There are reports suggesting that executive control may develop until the period of young adulthood, i.e., roughly up to 25 years of age (Casey et al., 2008). There is also ample evidence that adolescence is a period of life during which such abilities as impulse control or delay of gratification are still immature (Steinberg, 2007, 2010). If executive control is not properly developed at the pre-adolescent and adolescent periods of development, huge inter-individual differences in EF must occur among school-age children (Duckworth, Gendler, \& Gross, 2014). If so, one should expect that children's individual development of executive control would be a strong predictor of Gf, maybe stronger than among normally functioning adults. We hypothesize that fluid intelligence of children at the age 10-13 would depend on both storage capacity and executive control. The question of relative importance of these two predictors remains open to exploratory analyses.

\section{Method}

\section{Participants}

We investigated 96 schoolchildren, aged 10-13, $\mathrm{M}=12.03, \mathrm{SD}=1,51$ girls and 45 boys. They were recruited from two secondary schools in Bialystok, Poland. Written informed consent forms have been obtained from parents or legal guardians of participants. The children had free choice concerning their participation in the experiment.

\section{Materials \\ The n-back task \\ We used the figural version of the n-back task, the same as in Experiment 5 reported by Chuderski and Nęcka}

(2012). The task consisted in serial presentation of simple figural symbols, such a star, a triangle, an arrow etc., each approximately $2.5 \times 2.5 \mathrm{~cm}$ in size. Stimuli remained at the screen for $1500 \mathrm{~ms}$ and were masked for $300 \mathrm{~ms}$. The task consisted of four series. In every series we presented 88 stimuli, so altogether there were 352 stimuli showed to each participant, plus some training stimuli before each series. Sixteen out of 88 stimuli in every series were presented twice. The participants were supposed to decide whether the second presentation took place $n$ elements after the first one. The predefined $n$ number equaled two. Hence, participants were instructed to press a space bar if and only if the currently presented symbol had already appeared two items back. For instance, if a symbol reappeared in the stream of stimuli separated by just one other symbol (e.g., star, triangle, star again) this repeated symbol became a target that required detection and speedy response with the space bar. If an item reappeared too early, i.e., immediately after its first presentation, or too late, i.e., separated by two symbols instead of just one, it was to be ignored. Stimuli reappearing too early $(n=1)$ or too late $(n=3)$ were classified as "lures", since their function was to "tempt" participants to respond with no required accuracy. There were eight targets, four $\mathrm{n}=1$ lures, and four $n=3$ lures in every series. Majority of stimuli (72 in every series) did not reappear shortly after their first presentation". These stimuli may be termed "noise", since they were to be ignored. If a participant responded to such stimuli, he/she committed the error of false alarm. Also, if a participant pressed the space bar in response to the stimuli that reappeared at "wrong" positions, i.e., $n=1$ or $n=3$, he/she earned the error of lure detection. We registered accuracy scores for each participant, defined as the proportion of correct signal detections and the proportion of erroneous lure detection. We also registered reaction time of every response but these data will not be analyzed and reported here.

\section{Raven's Progressive Matrices}

We used Raven's Progressive Matrices (Raven, Court, \& Raven, 1983) in the Polish adaptation (Jaworowska \& Szustrowa, 2010) as a tool to assess children's fluid intelligence. This test consists of 60 items divided into five series. Each series consists of 12 abstract reasoning tasks arranged according to their increasing difficulty (the rule of progression). All items are based on Spearman's (1927) idea of eduction of relations, since they can be solved only if a person is able to grasp abstract relations between figural symbols. The test takes 40 minutes to complete.

\section{Test for Creative Thinking - Drawing Production}

In order to assess if the hypothesized relationships would be specific to intelligence, we decided to use another ability test. We chose the Test for Creative Thinking Drawing Production, created by Urban and Jellen (1986) in the Polish adaptation by Matczak, Jaworowska \& Stańczak (2000). This test consists of an A4 sheet of paper, on which

\footnotetext{
${ }^{1}$ Although repetition of stimuli was inevitable taking into account the length of each series.
} 
a frame and six small elements are drafted. The instruction says that an artist has not finished the drawing and therefore the participant must complete it on his/her own. Fifteen minutes maximum is allowed for the test completion. Scoring is based in the formal and objective criteria, such as the number of continuations, completions etc.

\section{Procedure}

Participants took part in three testing sessions. During the first session they completed the n-back task, working in the school computer room. There were 6-7 children working simultaneously under the experimenter's supervision, in the conditions that ensured silence and lack of distraction. Each of the three segments of the task was preceded by short training series. The whole procedures took about 30 minutes to complete, including instruction, training, and technical breaks between series. The second session served for testing with the TCT-DP, and the third one allowed testing with Raven's matrices. The sessions were separated by periods lasting from two to three weeks, and the whole procedure of data gathering took about three months altogether.

\section{Results}

Table 1 shows descriptive statistics for the following variables: the mean proportion of errors in the $n=1$ condition (ERR $n=1)$, the mean proportion of hits in the $n=2$ condition (HIT $n=2$ ), and the mean proportion of errors in the $n=3$ condition (ERR $n=3$ ). Statistics concerning Raven's Progressive Matrices (RPM) and the Test for Creative Thinking - Drawing Production (TCT-DP) are also included. We can see that the mean hit rate slightly exceeded 0.50 , which was the guess point. It means that the average accuracy, measured with the proportion of properly detected signals, was not very high, although the mean hit rate (0.60) differed significantly from the guess point: $t(1,95)=5.45, p<.001)$. As to error rate, we found quite high proportion of false alarms $(0.48)$ in the $\mathrm{n}=1$ condition, and quite low proportion of false alarms in the $n=3$ condition. Mean error rate in the $n=1$ condition did not differed statistically from the point of random decision: $t(1,95)=-0.74, p=.46$, whereas the mean error rate in the $\mathrm{n}=3$ condition did: $t(1,95)=-8.54, p<.001$. The observation that mean accuracy measures in the $\mathrm{n}=1$ and $n=2$ conditions were not quite impressive made us decide to conduct further analyses not only with the whole sample but also with participants selected on the basis of their high accuracy scores. As to the ability measures, both RPM and TCT-DP brought about the average results that seemed typical for the population from which our sample was recruited.

The indices of skewness and kurtosis shown in Table 1 suggest possible deviation from the parameters of normal distribution. The K-S test revealed that all dependent variables included in Table 1 were not normally distributed. Error rate indices in the $n=1$ and $n=3$ conditions were slightly left-sided and the hit rate indices in the $n=2$ condition was a bit right-sided. These observations suggest that the majority of participants responded with acceptable accuracy, so lack of normality of distribution resulted from high error rate committed by the minority. In order to eliminate statistical problems connected with normality of distribution, all dependent variables were subjected to logarithmic transformation.

In Table 2 we report zero-order correlation coefficients. We found only one significant correlation between scores in Raven's matrices and n-back performance measures. It appeared that higher scores in RPM were associated with relatively low proportion of false alarms in the $\mathrm{n}=1$ condition $(r=-0.36, p<0.001)$. Correlations pertaining to the $\mathrm{n}=2$ and $\mathrm{n}=3$ conditions, although consistent in sign with our predictions, did not exceed the significance levels. Analogical correlation between error rate in the $\mathrm{n}=1$ condition and the creativity test was significant, too, albeit a bit weaker $(r=-0.27$, $p=0.01)$. Table 2 also shows significant positive correlation coefficients between three measures of n-back performance. We can see that error rate indices in the $\mathrm{n}=1$ and $\mathrm{n}=3$ conditions were correlated at the level of $r=0.53$, $p<0.001$, which is not surprising since both measures reflect inhibitory control. Interestingly, the hit rate in the

Table 1. Descriptive statistics

\begin{tabular}{lccccccccc}
\hline & & N & Min & Max & Mean & SD & \multicolumn{2}{c}{ Skewness } & Kurtosis \\
\hline ERR & $\mathrm{n}=1$ & 96 & 0.00 & 1.00 & 0.48 & 0.32 & 0.09 & -1.36 \\
\hline HIT & $\mathrm{n}=2$ & 96 & 0.22 & 1.00 & 0.60 & 0.18 & -0.36 & -0.62 \\
\hline ERR & $\mathrm{n}=3$ & 96 & 0.00 & 0.94 & 0.32 & 0.21 & 0.58 & -0.33 \\
\hline RPM & & 96 & 14 & 55 & 42.27 & 7.36 & -1.26 & 3.16 \\
\hline TCT-DP & & 96 & 8 & 57 & 28.08 & 7.36 & 0.17 & -0.80 \\
\hline
\end{tabular}

Note:

ERR - error rate, proportion of false alarms

HIT - hit rate, proportion of properly detected signals

RPM - Raven's Progressive Matrices

TCT-DP - Urban and Jellen's Test for Creative Thinking - Drawing Production 
$\mathrm{n}=2$ condition correlated positively with the error rate in the $\mathrm{n}=3$ condition $(r=0.49, p<0.001)$ but not in the $\mathrm{n}=1$ condition $(r=0.04, p<0.74)$. The former result suggests that, in the $\mathrm{n}=3$ condition, participants might have sometimes treated lures as signals, thus committing false alarms without awareness of responding to lures instead of signals (see: Chuderski \& Nęcka, 2012, for similar interpretation). The latter finding suggests that participants generally did not adopt the strategy of pressing the space bar all the time "just in case". If they did, we should expect significant positive correlation between error rate in the $\mathrm{n}=1$ condition and hit rate in the $\mathrm{n}=2$ condition, which was not the case. Nevertheless, some participants could adopt such a strategy, which is reflected by not very good indices of accuracy, reported in Table 1 .

In order to check whether the relationships reported in Table 2 pertain to each ability measure if another one is controlled for, we conducted a series of partial correlation analyses. The partial correlation between RPM scores and error rate in the $\mathrm{n}=1$ condition did not change significantly when TCT-DP scores were controlled for $(r=-0.35$, $p<0.001)$. Analogically, the partial correlation between TCT-DP scores and error rate in the $\mathrm{n}=1$ condition ( $r=-0.25, p<0.01)$ was almost identical with the zero-order correlation. This pattern of relationships is understandable taking into account that scores in the intelligence and creativity tests were not mutually correlated (see Table 1).

Next, we built a regression model in which Raven's scores were defined as the dependent variable and three accuracy scores of the n-back task served as predictors. We found the following parameters of the model: $R=0.408$, $R^{2}=0.166$, corrected $R^{2}=0.139, F(3,92)=6.107$, $p=0.001$. We also found the following beta coefficients: ERR $\mathrm{n}=1, \beta=-0.347, p<0.004$; HIT $\mathrm{n}=2, \beta=0.201$, $p=0.082$; ERR $\mathrm{n}=3, \beta=-0.044, p=0.746$. From these results we can draw a conclusion that inhibition of impulsive albeit wrong responses in the $n=1$ condition is really a significant predictor of Gf. As to detection of signals in the $\mathrm{n}=2$ condition, the results seem discouraging, although the $p$ value in the regression model appeared marginally significant $(\beta=0.201, p=0.082)$. We also computed analogical regression analysis with TCT - DP scores as the dependent variable. This time the model was not fit well enough: $R=0.270, R^{2}=0.073$, corrected $R^{2}=0.043$, $F(3,92)=2.420, p=0.071$. The beta index for the error rate in the $\mathrm{n}=1$ condition slightly exceeded the significance level ( $(=-0.248, p=0.051)$. Thus, inhibitory control reflected by low error rate in the $n=1$ condition appears to predict creativity with disputable strength, while its predictive power pertaining to Gf seems unquestionable.

Taking into account the possibility that some participants could adopt the strategy of pressing the bar "just in case", thus emitting both correct responses in the $n=2$ condition but also false alarms in the $n=1$ condition, we decided to repeat the correlational analyses with participants characterized by high accuracy scores. We selected participants whose hit rate in the $n=2$ condition significantly exceeded the guess point of 0.50. The selection criterion was the hit rate higher or equal 0.64 , because we found that the $95 \%$ confidence interval of remaining above the chance level was 0.1359 $(0.50+0.1359 \approx 0.64)$. Only 45 participants remained in the selected subsample, which is a bit problematic as to degrees of freedom and restriction of variance. Nevertheless, the correlation coefficients reported in Table 3 seem worth the risk caused by sample size reduction. We can see that the Raven scores correlation with error rate in the $\mathrm{n}=1$ condition was stronger than in the whole sample $(r=-0.42, p=0.004$ and $r=-0.36$, $p<0.001$, respectively), although the $p$ value is a bit weaker due to reduced sample size. We can also see that RPM scores were negatively correlated with error rate in the $\mathrm{n}=3$ condition $(r=-0.33, p=0.03)$, which means that high IQ participants tended to avoid impulsive responding in this relatively demanding condition. It must be underscored that selection of participants on the basis

Table 2. Zero-order correlation coefficients for the whole sample, $N=95$

\begin{tabular}{|c|c|c|c|c|c|}
\hline & ERR $n=1$ & HIT $n=2$ & $\mathrm{ERR} n=3$ & RPM & TCT-DP \\
\hline $\mathrm{ERR} n=1$ & - & $\begin{array}{c}.04 \\
p=.74\end{array}$ & $\begin{array}{c}.54^{* * *} \\
p<.001\end{array}$ & $\begin{array}{c}-.36^{* * *} \\
p<.001\end{array}$ & $\begin{array}{c}-.27^{* *} \\
p=.01\end{array}$ \\
\hline HIT $n=2$ & - & - & $\begin{array}{c}.49^{* * *} \\
p<.001\end{array}$ & $\begin{array}{c}.17 \\
p=.10\end{array}$ & $\begin{array}{c}-.01 \\
p=.90\end{array}$ \\
\hline $\mathrm{ERR} n=3$ & - & - & - & $\begin{array}{c}-.13 \\
p=.19\end{array}$ & $\begin{array}{c}-.17 \\
p=.10\end{array}$ \\
\hline RPM & - & - & - & - & $\begin{array}{c}.10 \\
p=.33\end{array}$ \\
\hline
\end{tabular}

Note:

ERR - error rate, proportion of false alarms

HIT - hit rate, proportion of properly detected signals

RPM - Raven's Progressive Matrices

TCT-DP - Urban and Jellen's Test for Creative Thinking - Drawing Production 
of their accuracy scores must have resulted in restriction of variance, which normally makes correlation coefficients weaker rather than stronger. Therefore, these findings seem quite convincing as to the claim that general fluid intelligence is predicted by efficient inhibitory control. Remarkably, no significant correlation with hit rate in the $\mathrm{n}=2$ condition occurred $(r=0.03, p=0.85)$. Table 3 also demonstrates that none of the n-back task performance indices was related to creativity level, since all correlation coefficients with TCT-DP lost their significance after selection of participants on the basis of the accuracy scores. It seems, therefore, that the findings reported in Table 2 and Table 3 are specific to fluid intelligence, with no generalization on other dimensions of cognitive abilities.

\section{Discussion}

In an attempt to find out which aspects of working memory account for general fluid intelligence (Gf), we conducted an experimental study with the participation of 96 school-age children. The participants completed a special version of the n-back task, which required detection of signals, i.e., stimuli repeated at the valid $n=2$ position, and neglect of lures, i.e., stimuli repeated too early $(\mathrm{n}=1)$ or too late $(n=3)$. We hypothesized that high proportion of signal detection would reflect large capacity of the focus of attention (Cowan, 2001), whereas low proportion of responses to lures would reveal the efficacy of executive control, particularly - strength of the prepotent response inhibition (Miyake et al., 2000). These two aspects of working memory efficiency - capacity and control showed their contribution to Gf in previous studies with adult participants, the former seeming more important than the latter (Chuderski \& Nęcka, 2012). We found that Gf, assessed with Raven's matrices, did not enter in any relationship with the proportion of signal detection. Conversely, the proportion of false alarms in the $n=1$ condition showed significant negative correlation with Raven. We can therefore conclude that the capacity aspect of working memory turns out to be insignificant for Gf, whereas the control aspect is an important predictor of Gf, accounting up to $20 \%$ of its variance. So, the capacity vs. control debate obtained empirical evidence favoring the executive control stance, as far as children's intelligence is concerned.

Although our findings are compatible with results reported by other authors (e.g., Hasher, Lustig, \& Zacks, 2007) it is nevertheless puzzling that they are not compatible with the results of the former study (Chuderski \& Nęcka, 2012), which was based on exactly the same methodology (see also: Chuderski et al., 2012). Here, we suggest an explanation of this discrepancy. It is possible that fluid intelligence is developing not only in terms of its general level, or efficiency, but also in terms of the nature of cognitive processes involved in human intellectual functioning. In other words, quantitative individual differences in Gf, reflected by IQ tests scores, may depend on qualitative differences in the type of cognitive processes forming intellectual capabilities of the person. For some people, storage capacity may be more important as a determinant of Gf, whereas others probably capitalize on executive functions, including inhibitory control. It seems that adults are rather dependent on storage capacity (Chuderski \& Nęcka, 2012; Chuderski et al., 2012) but the category of control-dependent persons may be overrepresented among school-age children.

Let us look at the obtained results from the perspective of the theory of cognitive development. Children at the age between 10 and 13 years are in a very specific point of the developmental trajectory. On the one hand, their level of general fluid intelligence is not steady yet, since the IQ stabilization takes place in early adulthood (Belsky, 1990; Li, Lindenberg, Hommel, Aschersleben, Prinz, \& Baltes, 2004). So, there is still "something to be gained" in order to enter a higher level of intellectual development. On the other hand, executive control is still developing among children of this age (Duckworth et al., 2014), although the pace of development is slower than the one

Table 3. Zero-order correlation coefficients for the sub-sample of accurate participants, $N=45$

\begin{tabular}{|c|c|c|c|c|c|}
\hline & $\mathrm{ERR} n=1$ & HIT $n=2$ & $\mathrm{ERR} n=3$ & RPM & TCT-DP \\
\hline ERR $n=1$ & - & $\begin{array}{c}.26 \\
p=.08\end{array}$ & $\begin{array}{c}.72^{* * *} \\
p<.001\end{array}$ & $\begin{array}{c}-.42^{* *} \\
p<.004\end{array}$ & $\begin{array}{c}-.23 \\
p=.131\end{array}$ \\
\hline HIT $n=2$ & - & - & $\begin{array}{c}.31^{*} \\
p<.04\end{array}$ & $\begin{array}{c}.03 \\
p=0.85\end{array}$ & $\begin{array}{c}.00 \\
p=.99\end{array}$ \\
\hline $\mathrm{ERR} n=3$ & - & - & - & $\begin{array}{c}-.33^{*} \\
p=.03\end{array}$ & $\begin{array}{c}-.20 \\
p=.18\end{array}$ \\
\hline RPM & - & - & - & - & $\begin{array}{c}.10 \\
p=.33\end{array}$ \\
\hline
\end{tabular}

Note:

ERR - error rate, proportion of false alarms

HIT - hit rate, proportion of properly detected signals

RPM - Raven's Progressive Matrices

TCT-DP - Urban and Jellen's Test for Creative Thinking - Drawing Production 
observed between three and six years of age (Rothbart \& Rueda, 2005; Rueda et al., 2005). It is estimated that executive control stabilizes only in young adulthood, that is, between 18 and 25 years of age (Casey et al., 2008). Consequently, between 10 and 13 years of age children are still developing their executive functions, and the range of individual differences in executive control must be substantial. In other words, children at this stage of cognitive development must cope with the problems caused by underdeveloped executive control, particularly - inhibitory control (Steinberg, 2007, 2010). The better one copes, the higher he/she scores on IQ tests, and probably also on other measures of higher-order cognition. This line of theorizing implies that individual differences in Gf are predicted by those cognitive functions that are the most problematic for the particular population. If inhibitory control is problematic for pre-adolescent children, individual differences in cognitive control must be fundamental in accounting for individual differences in Gf. Normally functioning adults are probably less dependent on executive control, therefore, in their case, it is the storage capacity that counts much more as the predictor of Gf.

The ability to inhibit prepotent albeit inaccurate responses seems very important for complex reasoning tasks that reflect fluid intelligence. Inhibitory control prevents a person from acceptance of inappropriate solutions based on superficial similarities among the task's elements. Fluid intelligence is rooted in the ability to grasp and utilize deep similarities, relations, or analogies defining the task's structure (Cattell, 1971; Spearman, 1927). If a person is unable to grasp such relations, he/she will not be capable to deal with novel and complex problems, which is the core of general fluid intelligence. It may happen, though, that a person is in fact capable enough to grasp abstract relations but he/she is "lured" by more salient yet irrelevant aspects of the task's structure. Therefore, inhibitory control over the "lures" must be viewed as a precondition of intelligent behavior. Maybe this factor is less important for adult mature intelligence but it seems crucial for school-age children whose intelligence is still quickly developing.

It must be underscored that our study suffers from certain weaknesses and limitations that undermine conclusiveness of its results. The sample was not very large compared to similar studies, including the ones that inspired us (Chuderski \& Nęcka, 2012; Chuderski et al., 2012). Moreover, almost half of the sample did not fulfill the accuracy criterion we have established for the selection of participants. After preliminary analyses on the whole sample we decided to exclude participants who did not respond above the chance level. It appeared that 41 participants out of 96 had to be excluded. Nevertheless, both the whole sample and the reduced subsample provided similar results, in spite of the reduction of degrees of freedom and inevitable loss of statistical power. Finally, we applied just one computerized task instead of a kind of small battery of tasks allowing assessment of two aspects of working memory: storage capacity and executive control. This decision resulted from the necessity to protect children from excessive amount of work and fatigue as a very likely consequence of increasing the number of tasks. Still, this decision, plus relatively small sample size, excluded the possibility to apply the latent variable approach, which might have brought about stronger and better-defined relationships between investigated constructs. In future replications, it would be advisable to increase the sample size and to make the working memory tasks friendlier for school-age children, in the hope to reduce the mean error rate.

\section{References}

Ackerman, P. L., Beier, M. E., \& Boyle, M. O., (2005). Working memory and intelligence: The same or different constructs? Psychological Bulletin, 131, 30-60.

Baddeley, A. (1986). Working memory. Oxford, UK: Clarendon Press.

Baddeley, A. (2002). Is working memory still working? European Psychologist, 7(2), 85-97.

Baddeley, A. D., \& Hitch, G. J. (1974). Working memory. In G. H. Bower (Ed.), Recent Advances in Learning and Motivation, Vol. VIII. New York: Academic Press.

Belsky, J. K. (1990). The psychology of aging: Theory, research, and interventions. Pacific Grove: Brooks/Cole Publishing Company.

Białecka-Pikul, M. (2012). Narodziny i rozwój refleksji nad myśleniem [Birth and development of deliberation about thinking]. Kraków: Wydawnictwo UJ.

Casey, B. J., Getz, S., \& Galvan, A. (2008). The adolescent brain. Developmental Review, 28(1), 62-77.

Cattell, R. B. (1971). Abilities: Their structure, growth, and action. Boston: Houghton Mifflin.

Chuderski, A., \& Nęcka, E. (2012). The contribution of working memory to fluid reasoning: capacity, control, or both? Journal of Experimental Psychology: Learning, Memory, and Cognition, 38 (6), $1689-1710$.

Chuderski, A., Taraday, M., Nęcka, E., Smoleń, T. (2012). Storage capacity explains fluid intelligence but executive control does not. Intelligence, 40(3), 278-295.

Colom, R., Rebollo, I., Palacios, A., Juan-Espinosa, M., \& Kyllonen, P. C. (2004). Working memory is (almost) perfectly predicted by $g$. Intelligence, 32(3), 277-296.

Colom, R., Abad, F. J., Rebollo, I., \& Shih, P. C. (2005). Memory span and general intelligence: A latent variable approach. Intelligence, $33,623-642$.

Conway, A. R. A., Kane, M. J., \& Engle, R. W. (2003). Working memory capacity and its relation to general inteligence. Trends in Cognitive Sciences, 7, 547-552.

Cowan, N. (1995). Attention and memory: An integrated framework. New York: Oxford University Press.

Cowan, N. (2001). The magical number 4 in short-term memory: A reconsideration of mental storage capacity. Behavioral and Brain Sciences, 24, 87-114.

Cowan, N., Elliott, E. M., Saults, J. S., Morey, C. C., Mattox, S., Hismjatullina, A., \& Conway, A. R. A. (2005). On the capacity of attention: Its estimation and its role in working memory and cognitive aptitudes. Cognitive Psychology, 51, 42-100.

Cowan, N., Morey, C. C., Chen, Z., \& Bunting, M. (2007). What do estimates of working memory tell us? In N. Osaka, R. H. Logie, \& M. D'Esposito (Eds.), The cognitive neuroscience of working memory (pp. 43-58). Oxford, UK: Oxford University Press.

Daneman, M., \& Carpenter, P. A. (1980). Individual differences in working memory and reading. Journal of Verbal Learning and Verbal Behavior, 19, 450-466.

Daneman, M., \& Green, I. (1986). Individual differences in comprehending and producing words in context. Journal of Memory and Language, 25(1), 1-18.

Daneman, M., \& Merikle, P. M. (1996). Working memory and language comprehension: A meta-analysis. Psychonomic Bulletin \& Review, $3(4), 422-433$. 
De Smedt, B., Janssen, R., Bouwens, K., Verschaffel, L., Boets, B., \& Ghesquière, P. (2009). Working memory and individual differences in mathematics achievement: a longitudinal study from first grade to second grade. Journal of Experimental Child Psychology, 103 (2), 186-201.

Duckworth, A. L., Gendler, T. S., \& Gross, J. J. (2014). Self-control in school-age children. Educational Psychologist, 49(3), 199-217.

Eisenberg, N., Duckworth, A. L., Spinard, T. L., \& Valiente, C. (2012). Conscientiousness: Origins in childhood? Developmental Psychology.

Engle, R. W., \& Kane, M. J. (2004). Executive attention, working memory capacity, and a two-factor theory of cognitive control. In B. Ross (Ed.), The psychology of learning and motivation, Vol. 44, (pp. 145-199). New York, NJ: Elsevier.

Engle, R. W., Tuholski, S. W., Laughlin, J. E., \& Conway A. R. A. (1999). Working memory, short term memory, and general fluid intelligence: A latent variable approach. Journal of Experimental Psychology: General, 128, 309-331.

Friedman, N. P., Miyake, A., Corley, R. P., Young, S. E., DeFries, J. C., \& Hewitt, J. K. (2006). Not all executive functions are related to intelligence. Psychological Science, 17, 172-179.

Gottfredson, L. S. (1997). Mainstream science on intelligence: An editorial with 52 signatories, history, and bibliography. Intelligence, 24(1), 13-23

Gray, J. R., Chabris, C. F., \& Braver, T. S. (2003). Neural mechanisms of general fluid intelligence. Nature Neuroscience, 6, 316-322.

Hambrick, D. Z., Kane, M. J., \& Engle, R. W. (2005). The role of working memory in higher-level cognition: Domain-specific vs. domain-general perspectives. In R. J. Sternberg \& J. Pretz (Eds.), Cognition and intelligence: Identifying the mechanisms of the mind (pp. 104-121) Cambridge, UK: Cambridge University Press.

Henry, L. A., Messer, D. J., \& Nash, G. (2013). Executive functioning in children with specific language impairment. Journal of Child Psychology and Psychiatry, 53(1), 37-45.

Kane, M. J., \& Engle, M. J. (2002). The role of prefrontal cortex in working-memory capacity, executive attention, and general fluid intelligence: An individual-differences perspective. Psychonomic Bulletin \& Review, 9, 637-671.

Kane, M. J., \& Engle, R. W. (2003). Working-memory capacity and the control of attention: the contributions of goal neglect, response competition, and task set to Stroop interference. Journal of Experimental Psychology: General, 132(1), 47.

Kane, M. J., Hambrick, D. Z., \& Conway, A. R. A. (2005). Working memory capacity and fluid intelligence are strongly related constructs: Comment on Ackerman, Beier, and Boyle (2005). Psychological Bulletin, 131, 66-71.

Kane, M. J., Conway, A. R. A., Hambrick, D. Z., \& Engle, R. W. (2007). Variation in working memory capacity as variation in executive attention and control. In A. R. A. Conway, C. Jarrold, M. J. Kane, A. Miyake, \& J. N. Towse (Eds.), Variation in working memory (pp. 21-48). Oxford: Oxford University Press.

Kirchner, W. Y. (1958). Age differences in short-term retention of rapidly changing information. Journal of Experimental Psychology, 55, 352-358.
Kyllonen, P. C., \& Christal, R. E. (1990). Reasoning ability is (little more than) working memory capacity?! Intelligence, 14, 389-433.

Li, S.-C., Lindenberg, U., Hommel, B., Aschersleben, G., Prinz, W., \& Baltes, P. B. (2004). Transformations in the couplings among intellectual abilities and constituent cognitive processes across the life span. Psychological Science, 15(3), 155-163.

Matczak, A., Jaworowska, A., Stańczak, J. (2000). Podręcznik. Rysunkowy Test Twórczego Myślenia. TCT-DP [Manual. Test For Creative Thinking - Drawing Production. TCT-DP]. Warszawa: Pracownia Testów Psychologicznych PTP.

McErlee, B. (2001). Working memory and focal attention. Journal of Experimental Psychology: Learning, Memory, and Cognition, 27, 817-835.

Miyake, A., \& Shah, P. (Eds.). (1999). Models of working memory: Mechanisms of active maintenance and executive control. Cambridge, UK: Cambridge University Press.

Nęcka, E. (1992). Cognitive analysis of intelligence: The significance of working memory processes. Personality and Individual Differences, 13, 1031-1046.

Nęcka, E., Orzechowski, J. (2005). Higher-order cognition and intelligence. In R. J. Sternberg \& J. Praetz (Eds.), Cognition and intelligence: Identifying the mechanisms of the mind (pp. 122-141). Cambridge, UK: Cambridge University Press.

Oberauer, K., Schultze, R., Wilhelm, O., \& Süß, H.-M. (2005). Working memory and intelligence - their correlation and their relation: Comment on Ackerman, Beier, and Boyle. Psychological Bulletin, 131, $61-65$.

Oberauer, K., Süß, H.-M., Wilhelm, O., \& Sander, N. (2007). Individual differences in working memory capacity and reasoning ability. In A. R. A. Conway, C. Jarrold, M. J. Kane, A. Miyake, \& J. N. Towse (Eds.), Variation in working memory (pp. 49-75). Oxford, UK: Oxford University Press.

Oberauer, K., Süß, H.-M., Wilhelm, O., \& Wittman, W. W. (2008). Which working memory functions predict intelligence? Intelligence, 36 , 641-652.

Raven, J. C., Court, J. H., \& Raven J. (1983). Manual for Raven's Progressive Matrices and vocabulary scales (Section 4: Advanced Progressive Matrices). London: H. K. Lewis.

Rothbart, M. K., \& Rueda, M. R. (2005). The development of effortful control. In U. Mayr, E. Awh \& S. W. Keele (Eds.), Developing individuality in the human brain (pp. 167-188). Washington, D.C.: American psychological Association.

Rueda, M. R., Posner, M. I., \& Rothbart, M. K. (2005). The development of executive attention: Contributions to the emergence of self-regulation. Developmental Neuropsychology, 28(2), 573-594.

Spearman, C. (1927). The abilities of man. London: Macmillan.

Steinberg, L. (2007). Risk taking in adolescence: New perspectives from brain and behavioral science. Current Directions in Psychological Science, 16(2), 55-59.

Steinberg, L. (2010). A dual system model of adolescent risk-taking. Developmental Psychobiology, 52(3), 216-224.

Turner, M. L., \& Engle, R. W. (1989). Is working memory capacity task dependent? Journal of Memory and Language, 28(2), 127-154. 